\title{
Occurrence and Distribution of Chickpea Diseases in Central and Southern Parts of India
}

\author{
Raju Ghosh, Mamta Sharma ${ }^{*}$, Rameshwar Telangre, Suresh Pande
}

International Crops Research Institute for the Semi-Arid Tropics, Patancheru, India.

Email: ${ }^{*}$ mamta.sharma@cgiar.org

Received March $6^{\text {th }}, 2013$; revised April $5^{\text {th }}, 2013$; accepted April 14 $4^{\text {th }}, 2013$

Copyright (C) 2013 Raju Ghosh et al. This is an open access article distributed under the Creative Commons Attribution License, which permits unrestricted use, distribution, and reproduction in any medium, provided the original work is properly cited.

\begin{abstract}
A survey was conducted in 2010-2011 rabi cropping season to obtain information on the distribution and incidence of chickpea diseases in respect to soil type, cultivar used, seed treatment in central and southern parts of India. Local cultivars predominated in most farmers' fields $(25 \%-48 \%) .63 \%$ of the farmers were practices seed treatment with fungicide. Dry root rot and collar rot diseases were found at all of the sites and incidence ranged from $8.9 \%-10.3 \%$ and $7.1 \%-10.5 \%$ respectively irrespective of cultivar type and locations. Incidence of wilt and black root rot disease ranged from 9.7\% - 13.8\% and 6.6\% - 7.4\% respectively. Black root rot disease was found in Andhra Pradesh and Karnataka states only. The result indicated that dry root rot and collar rot is currently highly distributed in all surveyed chickpea growing areas of central and southern parts of India. Therefore, possible management options are vital to alleviate the problem.
\end{abstract}

Keywords: Chickpea; Seed Treatment; Fungi; Disease; Survey; India; Yield

\section{Introduction}

Chickpea (Cicer arietinum L.) is the most important pulse crop and India accounts for approximately $75 \%$ of world's chickpea production. It occupies an area of 8 mha and its production is $7.1 \mathrm{mt}$ with an average productivity of $885 \mathrm{~kg} \cdot \mathrm{ha}^{-1}$ (Economic survey 2009-2010). It is an essential source of inexpensive protein in many parts of the world for those who adhere to a vegetarian diet.

Despite the high total production, yields of chickpea are low due to many biotic and abiotic constraints. Among the biotic constraints more than 50 diseases have so far been reported on chickpea [1]. Among them soil borne diseases such as fusarium wilt (Fusarium oxysporum f. sp. ciceris), dry root rot (Rhizocotonia bataticola), collar rot (Sclerotium rolfsii) and black root rot (Fusarium solani) [2,3] are the major limiting factor in chickpea production. Only data on few specific diseases in chickpea are available from different states in India [4,5]. However no current information on occurrences and distribution of chickpea diseases in India is available.

Chickpea diseases may cause yield losses of up to $100 \%$ depending on time of infection [6]. The recommended method of managing the diseases is to use resis-

*Corresponding author. tant varieties. A number of improved chickpea diseaseresistant varieties have been multiplied and disseminated to farmers in many districts of India. However, their current prevalence in farmers' fields has not been documented.

Wilt is the major diseases occurs in all chickpea growing areas of the Indian sub-continent [7], however recently dry root rot and collar rot emerging as a major threat to chickpea production [6]. These diseases have become more important in recent years due to drastic climate change makes the crop more susceptible [6]. A comprehensive survey of chickpea diseases in central and southern parts of India was conducted in 2010-2011. The objectives of the survey were: 1) to find out the occurrence and distribution of chickpea diseases; 2) to find out the incidence of the diseases; 3) to assess the levels of resistance and susceptibility of the cultivars grown in farmers' fields.

\section{Methods}

\subsection{Areas Surveyed}

Survey was conducted between December and March 2010-2011 in the four major chickpea growing states (Andhra Pradesh, Karnataka, Madhya Pradesh and Chhat- 
tisgarh) in central and southern parts of India (Figure 1). The districts in each region were selected randomly. A total of 400 fields covering 17 districts were surveyed. The number of fields visited per district ranged from 20 to 30 and a distance of 15 - $20 \mathrm{~km}$ was allowed between sites, but the distance was greater where chickpea fields were far apart, resulting in a smaller number of sites visited in such districts.

\subsection{Data Collection}

A Global positioning system (GPS) based survey sheet was prepared to collect information on disease incidence, soil type, seed treatment with fungicide, cultivars grown, by the farmers. The name of variety of each chickpea plant sampled, and whether it was local or improved, was noted from the farmer.

\subsection{Data analysis}

Three $(1 \times 1 \mathrm{~m})$ quadret were randomly selected in each field in all of the four states surveyed and infected plants were counted in each quadret. Based on infected and total number of plants, disease incidence was calculated. Disease incidence of individual fields was used for cal- culating the mean incidence of each district and the district average was used to calculate the mean incidence of the state. These averages indicate relative prevalence of chickpea diseases in the surveyed sites.

Data recorded on each parameter (cultivar type, soil type and seed treatment) were averaged to obtain mean of the each parameter. Two-tailed t-test were used to analyze disease incidence between cultivar types, soil type and seed treatment in each states. Analyses were conducted using Genstat software version 3.2.

\section{Result}

\subsection{Cultivars and Incidence}

A total of 8 chickpea varieties (local or improved) were grown by the farmers in the 4 states (Andhra Pradesh, Karnataka, Madhya Pradesh and Chhattisgarh). 32.08\% of the farmers grew only local varieties, whereas $62.92 \%$ grew improved varieties (Table 1). Among the local varieties, Annigeri (19.23\%) and then Harbora (12.82\%) were most frequently grown by the farmers. However, among the improved varieties JG 11 (34.61\%) was the most commonly grown. Other improved varieties grown by the farmers of Andhra Pradesh, Madhya Pradesh,

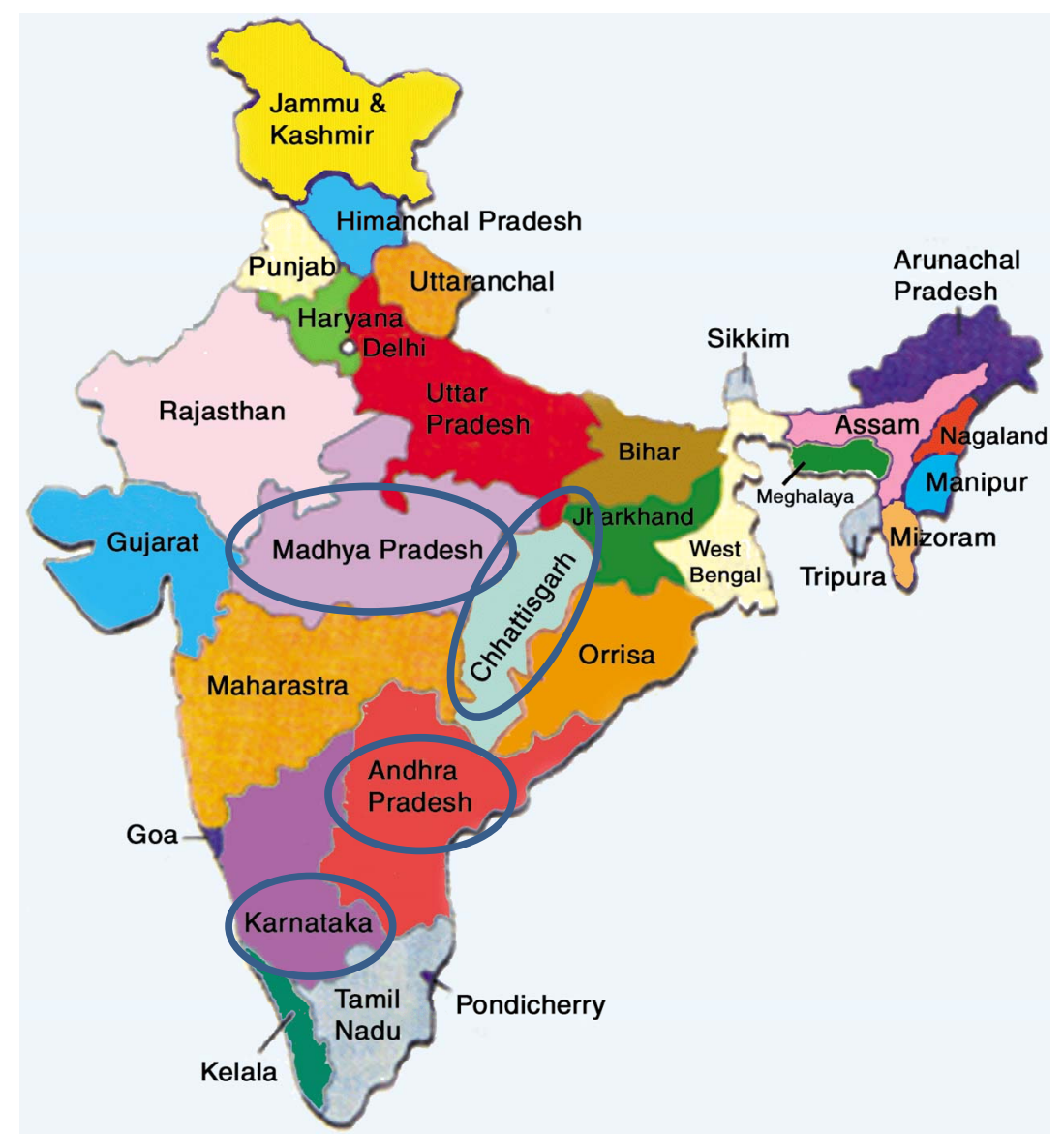

Figure 1. Surveyed locations during chickpea crop season in 2010-2011. 
Table 1. Percentage of farmers growing local and improved chickpea varieties in central and southern parts of India, 2010.

\begin{tabular}{|c|c|c|c|}
\hline State & District & Local (\%) & Improved (\%) \\
\hline \multirow{3}{*}{ Andhra Pradesh } & Kurnool & 42.10 & 57.90 \\
\hline & Anantpur & 44.45 & 55.55 \\
\hline & Mahboobnagar & 33.34 & 66.66 \\
\hline \multirow{4}{*}{ Madhya Pradesh } & Jabalpur & 20.00 & 80.00 \\
\hline & Rewa & 33.34 & 66.66 \\
\hline & Satna & 40.00 & 60.00 \\
\hline & Damoh & 25.00 & 75.00 \\
\hline \multirow{4}{*}{ Chhattisgarh } & Raipur & 20.00 & 80.00 \\
\hline & Durg & 16.67 & 83.33 \\
\hline & Rajnandgaon & 25.00 & 75.00 \\
\hline & Kabirdham & 40.00 & 60.00 \\
\hline \multirow{6}{*}{ Karnataka } & Dharwad & 33.34 & 66.66 \\
\hline & Raichur & 28.58 & 71.42 \\
\hline & Kolar & 80.00 & 20.00 \\
\hline & Bijapur & 37.50 & 62.50 \\
\hline & Gulbarga & 66.66 & 33.34 \\
\hline & Bidar & 44.45 & 55.55 \\
\hline Mean & & 32.08 & 62.92 \\
\hline
\end{tabular}

Chhattisgarh and Karnataka were JG 130, JG 16, JG 74 and Jawahar. High percentage of farmers (48\%) of Karnataka states used to cultivate local variety followed by Andhra Pradesh (39\%).

Disease incidence was lower on improved $(9 \%)$ as compared to local varieties (14\%) (Figure 2). The frequency of moderate to severe symptoms was higher on local varieties than on improved ones. Improved cultivar Jawahar showed high percentage of disease incidence (11\%) than other improved cultivar in Karnataka.

\subsection{Diseases and Regions}

Field surveys in 4 states showed that dry root rot (DRR) and collar rot (CR) predominant in all the fields. The other symptom distribution were wilt and black root rot (BRR) caused by Fusarium oxysporum f. sp. ciceris and Fusarium solani. Soil types had no significant effect on disease incidence in any of the regions surveyed.

\subsubsection{Andhra Pradesh}

In Andhra Pradesh all the four diseases (fusarium wilt, collar rot, dry root rot and black root rot) were found. Local cultivar had a higher incidence of wilt disease $(18.76 \%, \mathrm{t}=4.35, \mathrm{p}<0.04, \mathrm{df}=2)$ compared with improved cultivar (Table 2). DRR and CR disease incidence almost same $(6.31 \%-12.21 \%)$ irrespective of cultivars (local or improved) and soil types (Table 2). BRR disease was found at $100 \%$ of the fields in Andhra Pradesh irrespective of cultivar types. Seed treatment with fungicide (Bavistin) had a higher frequency of plants with lower incidence of all the diseases compared with untreated.

Table 2. Incidence of chickpea diseases in relation to various ecological variables in India, 2010.

\begin{tabular}{|c|c|c|c|c|c|c|c|c|c|c|c|c|c|c|}
\hline \multirow{3}{*}{ Parameters } & \multicolumn{14}{|c|}{ Disease incidence $(\%)$} \\
\hline & \multicolumn{4}{|c|}{ Andhra Pradesh } & \multicolumn{3}{|c|}{ Madhya Pradesh } & \multicolumn{3}{|c|}{ Chhattisgarh } & \multicolumn{4}{|c|}{ Karnataka } \\
\hline & FW & CR & DRR & BRR & FW & CR & DRR & FW & CR & DRR & FW & CR & DRR & BRR \\
\hline \multicolumn{15}{|l|}{ (a) Cultivar type } \\
\hline Local & 18.76 & 10.56 & 11.78 & 9.59 & 19.44 & 12.19 & 10.81 & 20.02 & 12.00 & 9.10 & 15.10 & 10.29 & 10.37 & 0.00 \\
\hline Improved & 9.86 & 6.31 & 9.67 & 5.85 & 0.00 & 6.86 & 9.85 & 0.00 & 9.68 & 8.77 & 8.78 & 10.24 & 10.30 & 14.89 \\
\hline \multicolumn{15}{|l|}{ (b) Soil type } \\
\hline Black & 14.31 & 8.43 & 10.72 & 7.72 & 19.44 & 9.25 & 10.35 & 19.58 & 11.07 & 11.09 & 11.94 & 10.27 & 10.33 & 0.00 \\
\hline Red & - & - & - & - & 0.00 & 7.54 & 9.78 & 20.67 & 8.75 & 9.38 & 19.83 & 8.25 & 10.00 & 14.89 \\
\hline \multicolumn{15}{|l|}{ (c) Seed treatment } \\
\hline Yes & 10.46 & 7.61 & 9.02 & 7.11 & 0.00 & 6.63 & 9.78 & 0.00 & 9.68 & 8.77 & 12.40 & 9.30 & 10.29 & 0.00 \\
\hline No & 16.81 & 9.72 & 12.21 & 9.22 & 19.44 & 11.60 & 10.75 & 20.02 & 12.00 & 9.10 & 14.86 & 12.40 & 10.46 & 14.89 \\
\hline
\end{tabular}

${ }^{*}$ FW: fusarium wilt; CR: collar rot; DRR: dry root rot; BRR: black root rot; ${ }^{\mathrm{a}}[$ Resistant $(\leq 10 \%)$, Moderately resistant $(10.1 \%-20.0 \%)$, Moderately susceptible $(20.1 \%-40.0 \%)$, and Susceptible $(40.1 \%-100 \%)]$; “-” indicate red soil type fields was not available. 


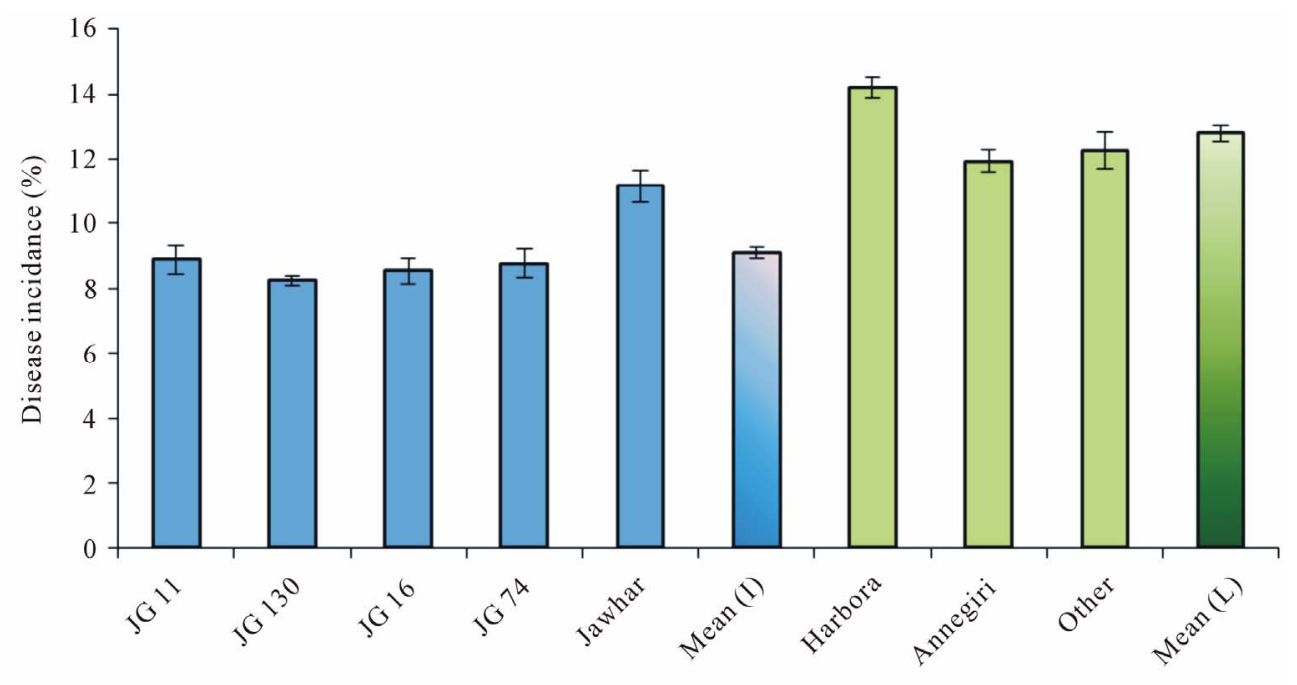

Cultivar

Figure 2. Disease incidence on improved (blue bars) and local (green bars) chickpea cultivar in central and southern parts of India, 2010. Means for the two cultivar categories are in bars filled in shaded color.

\subsubsection{Madhya Pradesh}

In Madhya Pradesh, three diseases were predominant (fusarium wilt, collar rot and dry root rot). No wilt incidence was recorded in improved cultivar grew by the farmers of Madhya Pradesh but local cultivar had higher incidence of wilt disease $(19.44, \mathrm{t}=18.21, \mathrm{p}<0.0001, \mathrm{df}$ $=4)$. DRR and CR disease incidence almost same irrespective of cultivars (local or improved) and soil types (Table 2). Seed treatment with fungicide (Bavistin) had a higher frequency of plants with lower incidence of all the diseases compared with untreated. No black root rot disease incidence was recorded in Madhya Pradesh.

\subsubsection{Chhattisgarh}

Pattern of disease incidence and distribution in Chhattisgarh was same as recorded in Madhya Pradesh. Fusarium wilt, collar rot, and dry root rot were the major limiting factors for chickpea production in Chhattisgarh. No wilt incidence was recorded in improved cultivar grew by the farmers of Chhattisgarh but local cultivar had higher incidence of wilt disease (Table 2). DRR and CR disease incidence almost same irrespective of cultivars (local or improved) and soil types (Table 2). Seed treatment with fungicide (Bavistin and thairam) had a higher frequency of plants with lower incidence of all the diseases compared with untreated. No black root rot disease incidence was recorded in Chhattisgarh.

\subsubsection{Karnataka}

In Karnataka all the four diseases (fusarium wilt, collar rot, dry root rot and black root rot) were found. Local cultivar had a higher incidence of wilt disease $(15.10 \%, \mathrm{t}$ $=3.20, \mathrm{p}<0.001, \mathrm{df}=11)$ compared with improved cultivar (Table 2). DRR and CR disease incidence almost same irrespective of cultivars (local or improved) and soil types (Table 2). Seed treatment with fungicide (Bavistin) had a higher frequency of plants with lower incidence of all the diseases compared with untreated. BRR disease was found at only $1 \%$ site of Karnataka in local cultivar.

\section{Discussion}

This study is the first to comprehensively examine the relative importance of fungal diseases of chickpea in central and southern parts of India compared to other chickpea diseases present in these states. Based on survey results, wilt incidence was ranked 1 st out of 4 chickpea diseases followed by DRR, CR and BRR. Thus, these diseases were found to be a relatively major disease of chickpea in central and southern parts of India during the survey.

Results of the present study indicated that wilt and BRR diseases of chickpea were restricted in local and moderately resistance chickpea cultivars irrespective of soil types. Distribution of BRR disease was only observed in Andhra Pradesh and Karnataka states of India. There are several possibilities to explain the low prevalence and incidence of BRR in Madhya Pradesh and Chhattisgarh irrespective of chickpea cultivars during the survey, including resistance, unfavorable environmental conditions for infection and disease development, and the increased use of seed treatments with fungicide.

Widespread distribution of DRR and CR in all chickpea cultivars was observed in all 4 states irrespective of cultivars grown by the farmers and it is a matter of concern. Average disease incidence of DRR and CR were varied from $8.9 \%-10.3 \%$ and $7.1 \%-10.5 \%$ on all the 
cultivars grown by the farmers'. The unpredictable moisture stress and higher temperatures in central and southern parts of India probably predisposed the chickpea crop to favorable conditions for DRR development [6]. Based on the results of this survey, the economic importance of these diseases was substantially higher. The high disease risks for DRR and CR were may be associated with the chickpea cultivars grown in central and southern India are susceptible to these pathogens. Although cultivar information was recorded from all the sites from which plants with DRR and CR symptoms were collected, DRR and CR resistance scores for these cultivars were not available. Little work has been done on the epidemiology of $R$. bataticola. Research done on $R$. bataticola showed that temperature and moisture stress are important for infection by $R$. bataticola [6]. High disease incidence on improved cultivar Jawahar may be due to old seed or mixture of seed used by the farmers of Karnataka states.

As expected, local cultivars had a higher disease incidence with more severe disease symptoms compared with improved varieties in all the 4 states of India. Improved cultivar (JG 130, JG 16 and JG 74) introduced in Madhya Pradesh and Chhattisgarh showed resistance to wilt and BRR diseases. Due to lack of the resistance source against DRR and CR diseases [8,9], the incidence and distribution of these two diseases was observed in all the fields irrespective of cultivar type.

The use of seed treatments on chickpea is increasing (Pande et al. unpublished), and this practice also may have played a role in the low prevalence of diseases. An estimated total of $63 \%$ of chickpea seed was treated with a fungicide. Seed treatment had a disease incidence ranged from $6.63 \%-12.40 \%$ compared with untreated $9.22 \%-20.02 \%$.

\section{Conclusion}

The distribution and incidence of soil borne diseases of chickpea varied in each state. DRR and CR diseases emerging as a potential threat to chickpea production.
Multiple disease resistant lines against wilt, DRR, CR and BRR vis-a-vis need to develop cultivars with combined resistance against these diseases. A detailed analysis of the factors responsible for widespread incidence of these diseases needs further investigations.

\section{REFERENCES}

[1] Y. L. Nene, V. K. Shelia and S. B. Sharma, "A World List of Chickpea and Pigeonpea Diseases," Legume Pathology Progress Report-7, ICRISAT Publication, 1989.

[2] M. P. Haware, Y. L. Nene and S. B. Mathur, "Seed Borne Diseases of Chickpea," Technical Bulletin 1, Danish Government Institute of Seed Technology for Developing Countries, Copenhagen, Vol. 1, 1986, pp. 1-32.

[3] Y. L. Nene, V. K. Shelia and S. B. Sharma, "A World List of Chickpea and Pigenpea Pathogens," 5th Edition, Patancheru, Andhra Pradesh, 1996, p. 27.

[4] A. Singh and A. Sirohi, "Status of Chickpea Diseases in Himachal Pradesh, India," ICPN, No. 10, 2003, pp. 2931

[5] P. S. Nikam, G. P. Jagtap and P. L. Sontakke, "Survey, Surveillance and Cultural Characteristics of Chickpea Wilt Caused by Fusarium oxysporium f. sp. ciceri," African Journal of Agricultural Research, Vol. 6, No. 7, 2011, pp. 1913-1917.

[6] S. Pande, S. Desai and M. Sharma, "Impacts of Climate Change on Rainfed Crop Diseases: Current Status and Future Research Needs," National Symposium on Climate Change and Rainfed Agriculture, Hyderabad, 18-20 February 2010, pp. 55-59.

[7] Y. L. Nene, "Diseases of Chickpea," Proceedings International Workshop on Chickpea Improvement, India, 28 February-2 March 1979, pp. 171-178.

[8] S. Pande, G. K. Kishore and J. N. Rao, "Evaluation of Chickpea Lines for Resistance to Dry Root Rot Caused by Rhizoctonia bataticola," ICPN, No. 11, 2004, p. 37.

[9] A. Akram, M. Iqbal, A. Rauf and R. Aleem, "Detection of Resistant Sources for Collar Rot Disease in Chickpea Germplasm," Pakistani Journal of Botany, Vol. 40, No. 5, 2008, pp. 2211-2215. 